\title{
TEM-SOFT: Academic Software for the Ergo-Mechanic Investigation of Tailgate Operation
}

\author{
Besim Türker Özalp \\ Industrial Engineering Department, Faculty of Engineering, Uludag University, Bursa, Turkey \\ Email: tozalp@uludag.edu.tr
}

How to cite this paper: Özalp, B.T. (2018) TEM-SOFT: Academic Software for the Ergo-Mechanic Investigation of Tailgate Operation. Journal of Software Engineering and Applications, 11, 383-407. https://doi.org/10.4236/jsea.2018.118024

Received: July 13, 2018

Accepted: August 20, 2018

Published: August 23, 2018

Copyright $\odot 2018$ by author and Scientific Research Publishing Inc. This work is licensed under the Creative Commons Attribution International License (CC BY 4.0).

http://creativecommons.org/licenses/by/4.0/

\section{(c) (7) Open Access}

\begin{abstract}
Because of their technical advantages over ordinary metal springs, gas springs find usage in wide range of applications from furniture to aerospace industry as lifting, lowering or damping assists. Their integration to the tailgate operations in automotive industry is a challenging area, where not only the fundamental gas spring characteristics but also the mounting settings, working environment and tailgate body structure should be considered. The design and integration of these components will determine manual force exertion of operators thus the consideration of ergonomic characteristics of different populations is crucial. This paper introduces a recent visual academic software package, entitled TEM-SOFT, which is developed as a part of this research to perform ergo-mechanic simulations of tailgate operations with a fast, reliable and contemporary engineering approach and it is suitable for engineers and under-post graduate level students of mechanical and industrial engineering programs in the universities. The software developed and presented in this paper features all aspects of tailgate-gas spring operations considering the assembly scheme, tailgate mass center, gas spring type and working temperature in order to compute the required manual forces and the individual and combined impacts of acting parameters. Sufficient amount of scenarios were considered and the results were evaluated and discussed extensively. In addition to the other key findings, conducted research has shown that stronger gas springs, more effectively tend to move the critical tailgate position angle-where no operator force is needed to keep the tailgate opening-to the initial phases of the opening operation. A trade-off of this benefit is a superior initial manual force during closing.
\end{abstract}

\section{Keywords}

Tailgate, Gas Spring, Ergonomics, Mechanics, Software 


\section{Introduction}

The terms design, analysis, sensitivity, rapidity and cost raise the stress on automotive engineers in today's global industrial challenge. Especially when the task becomes the simultaneous consideration of the mechanic force level, ergonomic suitability for the operator part, proper industrial actuator/damper selection and the assembly strategy of the actuator/damper on the vehicle body, scientific support expectation of the engineer becomes inevitable. Among the several application areas, such as safety mechanisms [1], medical equipment [2] and even for overload protection and force regulation [3], gas springs are also widely employed as both actuators and dampers in the automobile industry including cars, buses, trucks and construction machines. The cooperative function of the gas springs with the operators, structures the related research frame in the present scientific vision mainly on the following four key topics:

1) Concerns on force and ergonomics, covering the interaction of the rigid body dynamics parameters with operator functions.

2) Integration of automotive design with human factors, aiming to fit the structural design with anthropometric data.

3) Principles and design fundamentals of gas springs, including the physical description, compressible gas specifications and flexibility of assembly adaptation in the employed mechanism.

4) Computer aided design scopes in current engineering studies, indicating the advantages such as reliability, sensitivity, rapidity and scenario based adaptability.

With the progress of ergonomics as a science branch, the concepts of force and ergonomics are accustomed to be recognized in conjunction. Marcus et al. [4], indicating the significance of characterizing the associations between specific postures and musculoskeletal health, carried out a statistical investigation on various contributors to propose a suggestion system for reducing the risk of musculoskeletal symptoms and disorders. Mukhopadhyay et al. [5] as well investigated the discomfort measures on human body parts due to torque exposure during industrial activities. Due to the need on the development of a regression model for the ergonomic orientation of shoulder operation, Groot and Brand [6] worked on the recorded position data of a group of subjects, where the input parameters were the pre-defined posture of the subjects and the magnitude and direction of the external forces applied. To determine the maximal voluntary isometric forces for a variety of finger pulling tasks, Cort and Potvin [7] worked on seven operating conditions with a number of force application location and interface characteristics; their outputs have the potential to contribute to protecting worker health and safety and ensuring manufacturing quality. Lin et al. [8] explored the applications of a new model for predicting power threaded fastener-driving tool operator response and capacity to react against impulsive torque reaction forces for use in tool selection and ergonomic workplace design. To quantify the relative effect of the magnitude and direction of the exerted push 
force and of trunk inclination on the mechanical load at the low back using a regression analysis for correlated data, Hoozemans et al. [9] not only explored the effects of handle height and type of pushing activity when pushing a fourwheeled cart on a treadmill but also investigated the kinematics and measured the reaction forces on the hand to calculate the net moment. Due to the lack in the low cost predicting methods for observing biomechanical load on an operator during production in a workplace, Laring et al. [10] developed an ergonomic complement system that gives a first insight into the future ergonomic quality of a planned production; such that by initially identifying the events causing high biomechanical load on the operator, the production engineer gains the opportunity to redesign the process. Duprey et al. [11] discussed the challenge of measuring electromyographic (EMG) data in the field for the estimations of the muscular activations to ergonomically assess occupational tasks. The upper limb musculoskeletal (MSK) model from anybody was used for the prediction of joint reactions and muscle activations during a push force exertion task. The estimated results were compared with recorded ones performed by five healthy subjects equipped with EMG surface electrodes on the biceps, triceps, trapezius, anterior deltoid, and medial deltoid muscles. The results revealed that the patterns of the simulated activations from more recruited muscles were similar to the measured patterns. They concluded that the recorded signal patterns can correctly be reproduced by the MSK model for the shoulder muscles which are the most required in a lateral push task.

Automotive, being the leading industry in the global world, serves as an integration platform of several engineering disciplines. Among them kinematics, mechanics and ergonomics are accepted to be more pronounced when the focus is the physical interaction of the humans with car body parts. Reuding and Meil [12], by examining the ergonomics evaluation of a vehicle interior, which is a complex activity relying heavily on know-how gained from personal experience, investigated the predictive value of virtual reality and virtual environments when used for engineering assessment tasks. An integrated framework for vehicle interior design using a digital human model (DHM) was developed by Moonki et al. [13]. They implemented the knowledge-based parametric modeling function of vehicles using a commercial computer-aided design (CAD) system and reported the beneficial background attained by combining the DHM and the CAD systems which enables the designers into carrying out ergonomic evaluations of various human-vehicle interactions and understand the effects of modifications of vehicle design parameters on occupants during the design phase. Similarly in another study, researchers implemented virtual reality for the evaluation of car interiors and seating position of the driver. For their ergonomic assessments, digital human models were formed representing American male population in a semi-immersive virtual environment. They were able to make recommendations on driver's seating position without the need of physical prototypes [14]. Lamkull et al. [15] studied the factors owing to the appearance of virtual human models in the determination of the working posture; they not only demonstrated 
the difference between the showing and visually evaluating options of the human modeling tool, but also recommended a combination of visualizations and objective ergonomic assessment methods to minimize subjective effects. Joung et al. [16] developed a neutral schema to extend the abilities of a product lifecycle management system which utilizes an ergonomic simulator to analyze video recordings of the worker by managing forward-inverse kinematics and checklist-type ergonomic analysis techniques. They claim even a non-expert can perform ergonomic simulations by using this system. Fritzsche [17] declared the significance of the deviations among the digital human model simulations and real-life assessments; he suggested the incorporation of the comprehensive methods with simulation software to enhance the efficiency and the validity of digital ergonomics risk assessment. Gilad and Byran [18] emphasized the visual awareness of the driver when operating and controlling a vehicle. They developed a method for measuring and mapping the Field-of-View of the driver, incorporating computer simulations of a cockpit model and DHM positioned inside. Their approach differs from the previous methods by displaying quantitative data rather than qualitative results, thus the designer do not need to interpret the result in many ways, and take actions based on a trial and error, versus a scientific approach. A 3D worker simulation, in which DHM motions are automatically generated from textual descriptions, is currently being developed as part of an EU-funded project. Busemann et al. [19] suggested breaking down imperative sentences into a sequence of elementary actions, such as walk, pick, or place, carried out by virtual manikins using and manipulating objects in a $3 \mathrm{D}$ virtual car assembly shop-floor. Authors stated that their work promises an unequalled level of support to both plant planners and workers. A hierarchical controller framework was developed by Mårdberg et al. [20] for manikin motion planning aimed to reduce the time needed to perform virtual ergonomic assessments of manual assembly sequences. They realized and tested a general whole-body path planner in a virtual car manufacturing plant, which ensures collision-free and ergonomically sound motions that accomplish the assembly tasks. Wilder et al. [21] studied to determine whether a truck seat with a gas spring in its suspension, is superior to the standard spring seat in slowing the onset of muscle fatigue and reducing the level of discomfort experienced during road vibrations while maintaining typical driving postures. They concluded that fatigue and comfort measures can be used to detect postural defects, but the more sensitive measures of seat-driver interactions remain the mechanical ones, using motion-measuring techniques such as accelerometry and correcting the heavily damped nature of the system.

Scientists as well involved in industrial applications, where gas springs take part in the execution sequences. Besides, a number of researches also served to develop significant knowledge on the principles and design fundamentals of gas springs. Two different gas spring designs for a free-piston application were introduced by Pohl and Ferrari [22]; on the basis of thermodynamic calculations they analyzed a mass-variable and a volume-variable gas spring for different op- 
erating points. Cho et al. [23] carried out a work to satisfy the conditions for optimum design and recorded that the friction loss between the cylinder bore and the piston increases. In a supporting design work, Pereira and Deschamps [24] pointed out not only the significant impact of the proximity between the piston and the cylinder head on the flow field, but also the additional viscous friction force associated with the radial flow through the very narrow clearance left in the cylinder when the piston is close to the top dead center. Kornhauser [25] presented an elastic model, which is an improved prediction subroutine, with a series of dashpots and proper spring selection guidelines and damping constants. The combined effect of orifice flow and heat transfer on piston power dissipation of a gas spring has been evaluated within the framework of a small perturbation theory by Mirels [26], who figured out the relationship between piston displacement and gas spring pressure perturbation. In an accompanying heat transfer concern based study, Kornhauser and Smith [27] performed experiments on a piston-cylinder gas spring, by varying the speed, cyclic mean pressure, gas, bore/stroke ratio, volume ratio, and internal extended surface geometry. They measured hysteresis loss, pressure wave magnitude and pressure-volume phase shift.

Due to the complexity of the analysis and the design procedures in automotive industry, tackling with certain problems and detailing the comprehensive phenomena strongly confirm the need of specialized computer software support. Waterman [28] put forward the present industrial fact that, several global car manufacturers cut down the prototype expenses through trustable and robust virtual tests on simulated crash, suspension fatigue, fluid flow, performance, ergonomics, assembly sequencing, mold-flow, formability and welding. Aparicio et al. [29] developed a vehicle dynamics simulation program, which is capable of carrying out sensibility analysis of a 14-degrees of freedom system and justifying the effects using theoretical concepts. A software, to provide knowledge and to promote the experience of engineers and experts on the vehicle performance calculations, was developed by Calvo et al. [30]. Their new computational structure allows the design and calculations of dynamic mechanisms, which can be continuous-time, multi-rate discrete-time or virtually any combination of the two, with enough accuracy and by modifying the parameters that influence the performance values. Bylund [31] presented a software, which can support the design engineer, by carrying out the complex and iterative design and analysis processes of multipart mechanical structures faster and with high sensitivity. The main goals of the software are specified for the cases when considering the stiffness and interaction of the joints at the interior panels of the car body. A mathematical model, to analyze the hybrid vehicles and their components in detail was developed by Jimenez et al. [32]. The achievements of the model are explained as the possibility of modifying the internal parameters of the program, such as the vehicle energy, the flow control strategy and studying each component in detail. Fabian et al. [33] introduced an experimental vehicle, where its 
body was designed by means of 3D modelling using the CAD system CATIA V5. They used a module of the software to utilize materialization of the product images by simply pulling of the boundaries of a virtual sphere which is situated in the "control cage". They concluded that, with the help of newest CAx technologies together with printing possibilities of the 3D printers, even people short of practical skills in the area of CA-simulation processes can shorten the innovation time not only during development of the new motorcars, but also in all branches of the engineering industry.

The above defined past scientific investigations not only clearly identified the simultaneous presence of the issues related to force, ergonomics and automotive design based on human factors, but also formally denoted the broad industrial fields where the gas springs are employed with specific expectations. The contemporary scientific perspective strongly puts forward the reliable, sensitive, stable and fast progress of computer aided courses due to the quality and credibility of the results obtained. Especially for multi-factorial and interdisciplinary natured research frames of automotive design and engineering scopes [34] [35], similar to the coverage and aims of the present study, special simulation software support has become a custom industrial practice. Keller et al. [36] aimed to investigate the physiological and subjective responses of workers under different working conditions. The subjects volunteered to work with dry and oily hands and different type of screwdriver handles was examined. The handle with micro-textured single component surface shows the best results in terms of maximum torque exertion. Simultaneously physiological cost yielded by subjects examined through recording electromyographic activities of 4 muscles involved in the working tasks. It could be seen by all screwdrivers that $\mathrm{m}$. flexor digitorum was the dominantly involved muscle in screwing tasks. In another screwdriving task, mostly indigenous made handles were investigated. Additionally the subjects were asked to wear glove in screwing in and unscrewing tasks. EA activities from 5 different muscles were measured and subjective responses were also recorded through questionnaires. Significant differences were determined between maximum torque values produced during inward and outward rotations for the three operational cases. Maximum torque values exerted by 12 subjects using industrial gloves were substantially higher than the values obtained by dry and oily hands during both supination and pronation. EA results show that physiological cost values during supination is clearly higher contrarily to pronation [37].

In the present research, gas spring integrated tailgate operation of a vehicle, with the complete set of geometric, component based and operational parameters is investigated. Since the principle concern is the variation of manual forces of the operators during the opening and closing operations from ergonomic point of view, the major industrial and scientific aims and the novel contributions of the work are set as:

1) To establish the impact of assembly scheme of the gas spring with the vehicle and tailgate, from the point of manual force, human factors and self-lacking 
ability.

2) To identify the influence of the tailgate mass center location on the rigid body dynamics issues of the overall tailgate assembly.

3) To examine the task of gas spring nominal force level, in conjunction with the assembly scheme and the resulting manual force level.

4) To inspect the role of working temperature on the gas spring output force level and the corresponding outcomes.

5) To detail the individual and combined consequences of these agents.

This paper as well introduces a recent visual academic software package, entitled TEM-SOFT, which is developed as a part of this research, to accomplish the above objectives with a fast, reliable and contemporary engineering approach. TEM-SOFT computationally integrates the industrial and scientific knowledge of several disciplines on the simulation platform. TEM-SOFT provides the users to $\bullet$ Design and investigate the operation of the assembly scheme of the mechanism, which performs the opening and closing tasks of the tailgate, - Analyze the rigid body dynamics concerns of the mechanism to identify the component based force values, $\bullet$ Inspect the appropriateness of the complete assembly from the point of both physical functionality and ergonomic expectations, $\bullet$ Evaluate the manual forces during the opening and closing tailgate operations, $\bullet$ Compute the variation of the internal force values of gas springs, based on compressible gas principles, not only with working temperature but also during the tailgate operation, $\bullet$ Carry out tailgate analysis with real time gas spring alternatives, through the dynamic database link, $\bullet$ Update the contents of the gas spring database, in accordance with the arising technological and scientific necessities, - Report the computed outputs in terms of both graphical and documental means. In the present software-age, the outlined specifications are unique to TEM-SOFT, which clearly identifies its novel contribution to both academic purposes and industrial applications.

\section{Basics of Tailgate Operation}

\subsection{Current Situation}

As shown in Figure 1(a) the structure of the tailgate-gas spring assembly is characterized with a number of geometric definitions, such as the vehicle-tailgate hinge (VTH), tailgate side (TSH) and vehicle side (VSH) hinges of gas spring, tailgate mass center (TMC), handles for opening $(\mathrm{OH})$ and closing $(\mathrm{CH})$. The tailgate rotates around the axis of VTH during operation; as the VSH of the gas spring is fixed to the vehicle (Figure $1(\mathrm{~b})$ ), the TSH chases the tailgate body in the two-dimensional plane. The location of the TMC is a consequence of tailgate design and is not necessarily be within the rigid boundaries of the tailgate. The positions of the $\mathrm{OH}$ and $\mathrm{CH}$ are decided by the simultaneous consideration of the tailgate's physical outline and the ergonomic necessities of the design expectations. Besides, the locations of TSH and VSH considerably depend on the magnitude of the gas spring moment (Mgs) required on the tailgate. Mgs is 


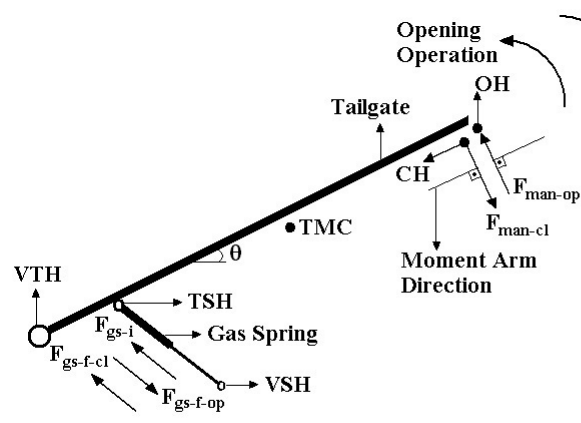

(a)

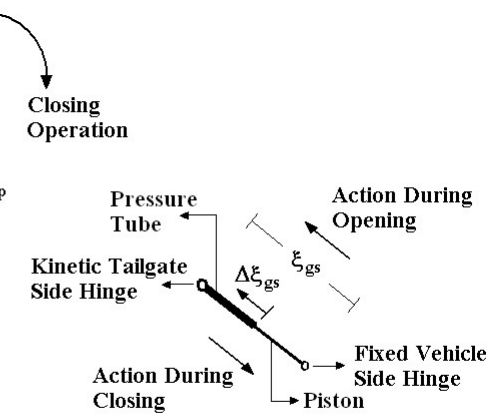

(b)

Figure 1. Structure of the tailgate-gas spring assembly.

primarily produced by the nominal force value $\left(\mathrm{F}_{\mathrm{gs-n}}\right)$ and the dimensions of the gas spring. Moreover, at the closed position $\left(\theta=0^{\circ}\right)$ of the tailgate, the length of the gas spring $\left(\zeta_{\mathrm{gs}}\right)$ is at its shortest measure; however expands with the relative motion of the pressure tube and the piston sections (Figure 1(b)) during the opening operation. Accompanying this mechanism action, the assembly strategy must satisfy the condition that the $\zeta_{\mathrm{gs}}$ attains its maximum possible physical extent $\left(\zeta_{\mathrm{gs-fo}}\right)$ at the fully open position of the tailgate.

The geometric design of the tailgate must basically satisfy the aerodynamic integrity of the overall vehicle body form, the aesthetic expectations and the need for the luggage compartment volume. Consequently its structural construction brings about the total weight value and the center of gravity, which are the closely inspected tailgate characteristics while selecting the most appropriate gas spring for the opening and closing operations. Although not recognized as a priority, the tailgate operation must encompass and ensure the ergonomic necessities as well. Since the weight exerts a moment on the tailgate in the closing direction, the manual force of the operator must be provided in accordance. In other words, the weight and the location of the mass center of the tailgate (TMC) need to be regarded as coupled-parameters. As the tailgate designs mostly resemble curved shapes, the mass centers may not be in the solid domain and on the symmetry axis but can lay within the area bounded by the arc-formed structure (Figure 1(a)). Besides, the positions and proportions of the glass and metal sections are as well significant on this issue.

The structural design process of the tailgate-gas spring assembly must satisfy the following 3 key points: 1 ) The negative value of the operator's manual force $\left(\mathrm{F}_{\operatorname{man}}\right)$ at the fully open position $\left(\theta=\theta_{\mathrm{fo}}\right)$ expresses that the tailgate will remain open; 2) During the opening process, at tailgate position angles above the critical value $\left(\theta>\theta_{\mathrm{cr}}\right)$ the condition of $\mathrm{F}_{\operatorname{man}}<0$ indicates that the tailgate will keep on opening without the manual force application of the operator; this condition is accepted as one of the essential specifications in the ergonomic design aspect; 3 ) In the closing operations, the tailgate is expected to self-lack without the application of $\mathrm{F}_{\text {man }}$, where this engineering prerequisite can be interpreted as $\mathrm{F}_{\text {man }}<0$ at $\theta=0^{\circ}$. 


\subsection{Theoretical Basics}

The analysis of tailgate operation with gas spring installation is based on the theories and approaches of compressible gas principles, mechanism guidelines and rigid body dynamics. Essentially, compressed nitrogen $\left(\mathrm{N}_{2}\right)$ in the pressure tube (Figure 1(b)) activates the force generation mechanism of the gas spring. The pressure level in the tube is specified at $\mathrm{T}=20^{\circ} \mathrm{C}$ and together with the piston cross-section area (Figure $1(\mathrm{~b})$ ) defines the nominal force of the gas spring $\left(\mathrm{F}_{\mathrm{gg}-\mathrm{n}}\right)$.

$$
\mathrm{F}_{\mathrm{gs}-\mathrm{n}}=\mathrm{F}_{\mathrm{gs}-\mathrm{n}-\mathrm{T}=20^{\circ} \mathrm{C}} *\left[1+\frac{(\mathrm{T}-20)}{10} * \frac{3.41297}{100}\right]
$$

The grade of nominal force not only labels the gas spring in the market, but also acts as the primary decisive parameter on the gas spring output force $\left(\mathrm{F}_{\mathrm{gs-o}}\right)$. Due to the augmentation of the pressure intensity of $\mathrm{N}_{2}$ in the tube with higher temperature, $\mathrm{F}_{\mathrm{gs}-\mathrm{n}}$ as well varies with working temperature where the relationship is characterized by Charles' Law as given by Equation (1) [38]. The compression coefficient $\left(\mathrm{C}_{\mathrm{gs}}\right)$, defined as the ratio of the tube pressure at the closed and fully open positions of the gas spring, is the second parameter, acting on $\mathrm{F}_{\text {gs-o }}$. The amount of compression is assumed to vary linearly $\left(\mathrm{C}_{\mathrm{gs}-\mathrm{p}}\right.$-Equation (2)) [38] with gas spring length change $\left(\Delta \zeta_{\mathrm{gs}}\right.$-Equation 3(a)), where the gas spring maximum length change $\left(\Delta \zeta_{\text {gs-max }}\right)$ is the difference among the fully open $\left(\zeta_{\text {gs-fo }}\right)$ and closed $\left(\zeta_{\text {gs-c }}\right)$ lengths of the gas spring (Equation 3(b)).

$$
\begin{gathered}
\mathrm{C}_{\mathrm{gs}-\mathrm{p}}=\frac{\left(\mathrm{C}_{\mathrm{gs}}-1\right) * \Delta \xi_{\mathrm{gs}}}{\Delta \xi_{\mathrm{gs}-\mathrm{max}}}+1 \\
\Delta \xi_{\mathrm{gs}}=\left|\xi_{\mathrm{gs}}-\xi_{\mathrm{gs}-\mathrm{fo}}\right|, \Delta \xi_{\mathrm{gs}-\mathrm{max}}=\xi_{\mathrm{gs}-\mathrm{fo}}-\xi_{\mathrm{gs}-\mathrm{c}}
\end{gathered}
$$

As a consequence, the internal force of the gas spring $\left(\mathrm{F}_{\mathrm{gs}-\mathrm{i}}\right)$, at any instant of the operation, is defined by Equation (4). Equations (2)-(4) reveals the dependence of $\mathrm{F}_{\mathrm{gs}-\mathrm{i}}$ not only on the structural positioning of the gas spring in-between the vehicle and tailgate, but also on the tailgate operation oriented structural dynamics of the gas spring itself.

$$
\mathrm{F}_{\mathrm{gs}-\mathrm{i}}=\mathrm{F}_{\mathrm{gs}-\mathrm{n}} * \mathrm{C}_{\mathrm{gs}-\mathrm{p}}
$$

Third parameter, characterizing the $\mathrm{F}_{\mathrm{gs-}-\mathrm{o}}$, is the friction force $\left(\mathrm{F}_{\mathrm{gs}-\mathrm{f}}\right)$ arising due to the relative motion of the tube and the piston during operation. The $\mathrm{F}_{\mathrm{gs}-\mathrm{o}}$ becomes enumerated with the co- or counter-directional contribution of $\mathrm{F}_{\mathrm{gs}-\mathrm{f}}$ as demonstrated in Figure 1(a) and Figure 1(b); where the resulting formulations are Equations (5a) and (5b) for opening and closing respectively.

The tailgate operation is a mechanism phenomenon, where the rotation action of the tailgate is followed by the two-dimensional response of the gas spring stimulated at the TSH. Mechanism analysis is carried out covering the complete angular domain starting from the closed, ending with the fully open $\left(\theta=0^{\circ} \rightarrow \theta_{\mathrm{fo}}\right)$ position of the tailgate; such that the locations of TSH, TMC, $\mathrm{CH}$ and $\mathrm{OH}$ are computed in the two-dimensional domain for the entire $\theta$ range. Evaluating 
TSH not only leads up to the identification of $\zeta_{\mathrm{gs}}, \Delta \zeta_{\mathrm{gs}}, \mathrm{C}_{\mathrm{gs}-\mathrm{p}}$ and $\mathrm{F}_{\mathrm{gs}-\mathrm{o}}$, but also the line of action of $\mathrm{F}_{\mathrm{gss}}$ for $\theta=0^{\circ} \rightarrow \theta_{\mathrm{fo}}$.

$$
\mathrm{F}_{\mathrm{gs}-\mathrm{o}}=\mathrm{F}_{\mathrm{gs}-\mathrm{i}}-\mathrm{F}_{\mathrm{gs}-\mathrm{f}}, \mathrm{F}_{\mathrm{gs}-\mathrm{o}}=\mathrm{F}_{\mathrm{gs-i}}+\mathrm{F}_{\mathrm{gs-f}}
$$

Since the aim is to compute the magnitude of the manual forces needed to operate the tailgate, the basic moment balance principle of rigid body dynamics is applied to every position $\left(\theta=0^{\circ} \rightarrow \theta_{\mathrm{fo}}\right)$ during the operation (Equation (6)).

$$
\left(\sum \mathrm{M}_{\mathrm{VTH}}\right)_{\theta=0^{\circ} \rightarrow \theta_{\mathrm{fo}}}=0
$$

Remembering the facts that the direction of the manual forces $\left(\mathrm{F}_{\operatorname{man}}\right)$ depend on the operation type and keep their perpendicular act to the moment arms for $\theta=0^{\circ} \rightarrow \theta_{\mathrm{fo}}$ (Figure 1(a)), the moment balance equation, in vector form, is developed in accordance with the related issues of opening (Equation (7a)) and closing (Equation (7b)) operations.

$$
\begin{aligned}
& |\overrightarrow{\mathrm{VTH}-\mathrm{TSH}}| \times \overrightarrow{\mathrm{F}_{\text {gs-o }}}+|\overrightarrow{\mathrm{VTH}-\mathrm{TMC}}| \times \overrightarrow{\mathrm{W}_{\mathrm{T}}}+|\overrightarrow{\mathrm{VTH}-\mathrm{OH}}| \times \overrightarrow{\mathrm{F}_{\text {man-op }}}=0 \\
& |\overrightarrow{\mathrm{VTH}-\mathrm{TSH}}| \times \overrightarrow{\mathrm{F}_{\text {gs-o }}}+|\overrightarrow{\mathrm{VTH}-\mathrm{TMC}}| \times \overrightarrow{\mathrm{W}_{\mathrm{T}}}+|\overrightarrow{\mathrm{VTH}-\mathrm{CH}}| \times \overrightarrow{\mathrm{F}_{\text {man-cl }}}=0
\end{aligned}
$$

In Equation (7), as the first term on the left is the gas spring moment $\left(\mathrm{M}_{\mathrm{gs}}\right.$-Equation (8)), the second one expresses the weight moment of the tailgate $\left(\mathrm{M}_{\mathrm{W}}\right.$-Equation (9)).

$$
\begin{aligned}
& \overrightarrow{\mathrm{M}_{\mathrm{gs}}}=|\overrightarrow{\mathrm{VTH}-\mathrm{TSH}}| \times \overrightarrow{\mathrm{F}_{\mathrm{gs}-\mathrm{o}}} \\
& \overrightarrow{\mathrm{M}_{\mathrm{W}}}=|\overrightarrow{\mathrm{VTH}-\mathrm{TMC}}| \times \overrightarrow{\mathrm{W}_{\mathrm{T}}}
\end{aligned}
$$

\section{TEM-SOFT: The Simulation Platform}

From not only industrial, but also scientific and academic perspective, tailgate operations with gas spring implementation cover; not only the investigation but also the design of the complete tailgate mechanism; not only the computation of force values of the assembly components but also the evaluation of the manual forces; not only the confirmation of the ergonomic suitability of the tailgate assembly but also the verification of its functionality; not only the estimation of working temperature dependence of internal force values of gas springs but also their variation during the tailgate operation based on compressible gas principles. The comprehensive theoretical content and its interdisciplinary character make it impossible to tackle with tailgate operations through custom methods or analytical calculations; thus a special software support appears as a contemporary requirement. Due to these facts, to numerically investigate the tailgate operations, the new software TEM-SOFT is developed as a part of this research. TEM-SOFT is structured to respond to the current technological and scientific requirements for the ergo-mechanic simulations of tailgate operations; which distinguishes it to be valuable both in the industrial and academic fields.

The code development of TEM-SOFT covers the scientific formulations governing the principles of compressible gas, mechanisms and rigid body mechan- 
ics; thus the computational necessities arise from the point of both run-speed and sensitivity. Due to these facts the basic PC-configuration, to run TEMSOFT, requires Intel i5 Processor with 4 GBytes RAM. TEM-SOFT is developed on Visual Basic. NET [39] programming domain; a dynamic database is as well constructed to carry out the analysis/design studies of tailgate operations with real-time gas springs.

To fulfill the overall requirements of the considered engineering problem, the algorithmic notion of TEM-SOFT is structured on five independent, but also linking, frameworks (FM). As shown in Figure 2, the FMs serve not only to carry on the tasks of "Project Orientation", "Database Operation", "System Configuration", "Analyze" and "Output Presentation", but also to guide the user and direct the analysis/design assignments by avoiding computational inconveniences and technical irregularities. Figure 2 further shows the sub-functions and the primary related parameters of each FM explicitly. Moreover, a private "Help Module" is also built in TEM-SOFT, to serve the users on possible queries.

The courses of the subroutines, fitted in each FM, communicate with the users through visual interfaces. The "Main Menu" and the "System Configuration" of TEM-SOFT are displayed in Figure 3. It can be seen from the figure that the complete geometric configuration and the supplementary data (Figure 2) can be input through the available text boxes of the specially designed interface. This input procedure is additionally accompanied and controlled by the "Internal Supervision Network" (ISN) [31] [32] of TEM-SOFT, which is not only responsible for the structural appropriateness of the input data, but also commanding the flow-order of the project management and subroutine integration of the FMs (Figure 2).

The access to the dynamic database (Figure 4) is provided through the associated link in the "Main Menu" (Figure 3); the already stored gas spring alternatives are available with their complete information on force scales and geometric sizes. Figure 4 further identifies the dynamic character of the database; such that as a new gas spring can be added to the database, the available alternatives can be deleted or updated as well. The "Analyze" FM not only takes the compressible gas phenomena into account, but also performs the calculations on mechanisms

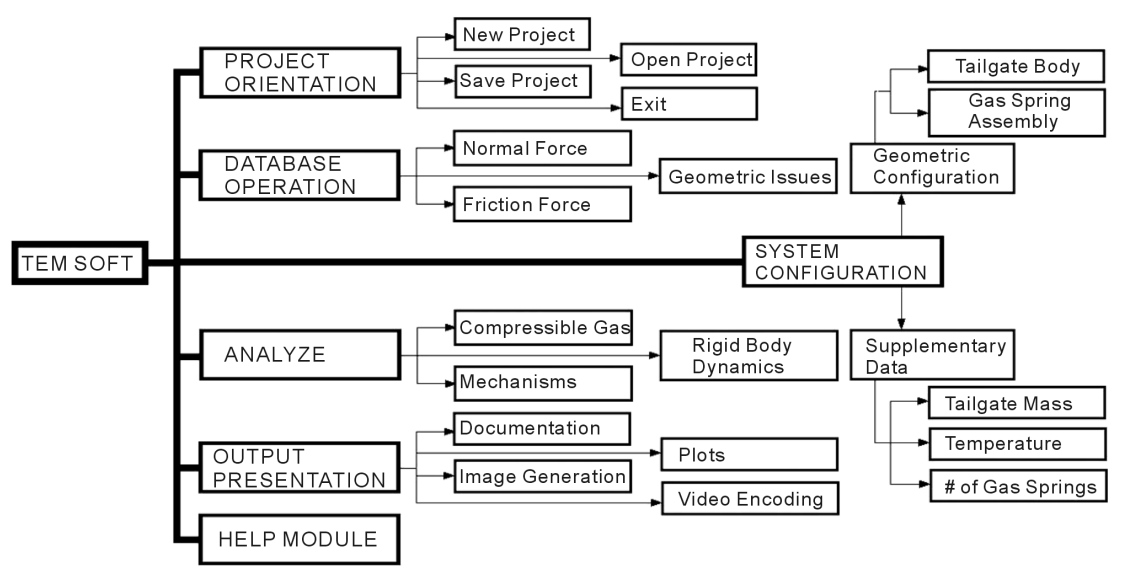

Figure 2. Frameworks of TEM-SOFT. 


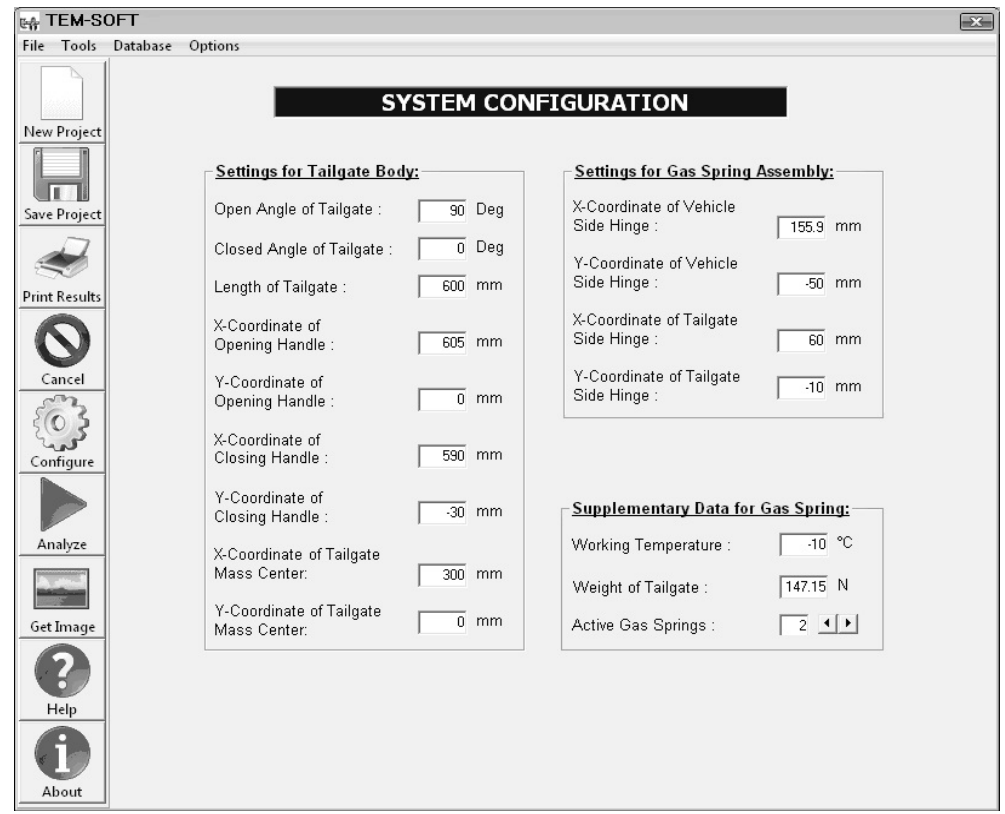

Figure 3. Main Menu-System Configuration of TEM-SOFT.

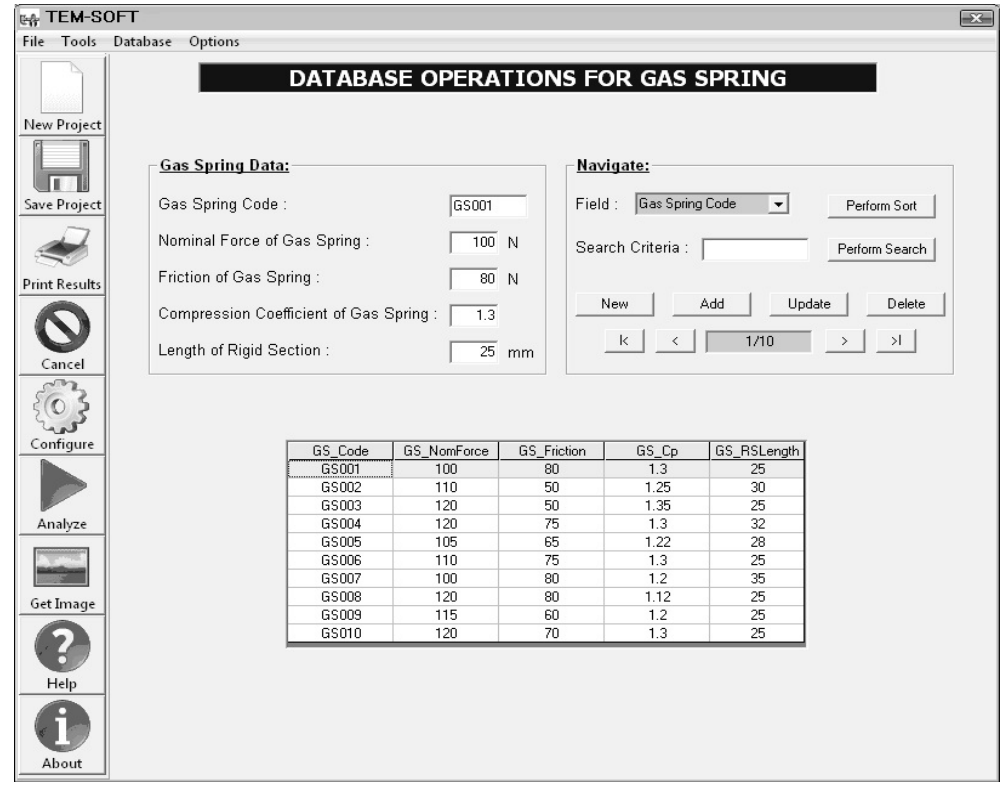

Figure 4. Database interface of TEM-SOFT.

and rigid body mechanics theories. The solution logic is mainly based on partitioning the angular operation domain of the tailgate into 1000 equal and sequential sub-cells and transmitting the neighboring cell information in-between. This computational attitude provides not only the continuous data integration in the solution domain, but also the investigation of the complete operation without discontinuities or instabilities. Lastly, the "Output Presentation" FM of TEM-SOFT is capable of delivering the computed outputs in the mostly recognized methods of documentation, plots, image generation and video encoding (Figure 2). In spite of the substantial output opportunities, TEM-SOFT brings out the "Major 
Functional Results" interface at the end of each run for technical inspection (Figure 5).

The described FM based algorithmic notion of TEM-SOFT assures the $\bullet$ design and investigation of the complete tailgate mechanism assembly, • evaluation of the component based force values with the rigid body dynamics analysis, - determination of the manual forces during the opening and closing tailgate operations, •verification of the functionality and ergonomic appropriateness of the complete tailgate assembly, $\bullet$ compressible gas principles based computation of the internal force variations of gas springs with working temperature and during the tailgate operation, • execution of tailgate analysis with real time gas spring alternatives, through the dynamic database link, $\bullet$ possibility of performing modifications in the gas spring database, $\bullet$ archiving of the computed outputs in terms of both graphical and documental formats. The overall structure of TEM-SOFT shows a distinctive integration of several capabilities, which as well identifies its novel task in the present software-age. Besides showing parallelism to other related software, they are mostly manufacturer's applications and designed for selecting gas springs from their inventory. Differently, TEM-SOFT enables user to develop custom gas springs through its "Database Operations" interface. Also the "System Configuration" FM where opening and closing handles are configured is highly comprehensive, which is significant in terms of ergonomic evaluations of operator manual forces.

\section{Results and Discussion}

Not only to demonstrate the computational capabilities of TEM-SOFT, but also to identify the individual and combined impacts of assembly scheme, mass center, gas spring type and working temperature a serious of successive computations are performed. The structural parameters such as the length and weight of

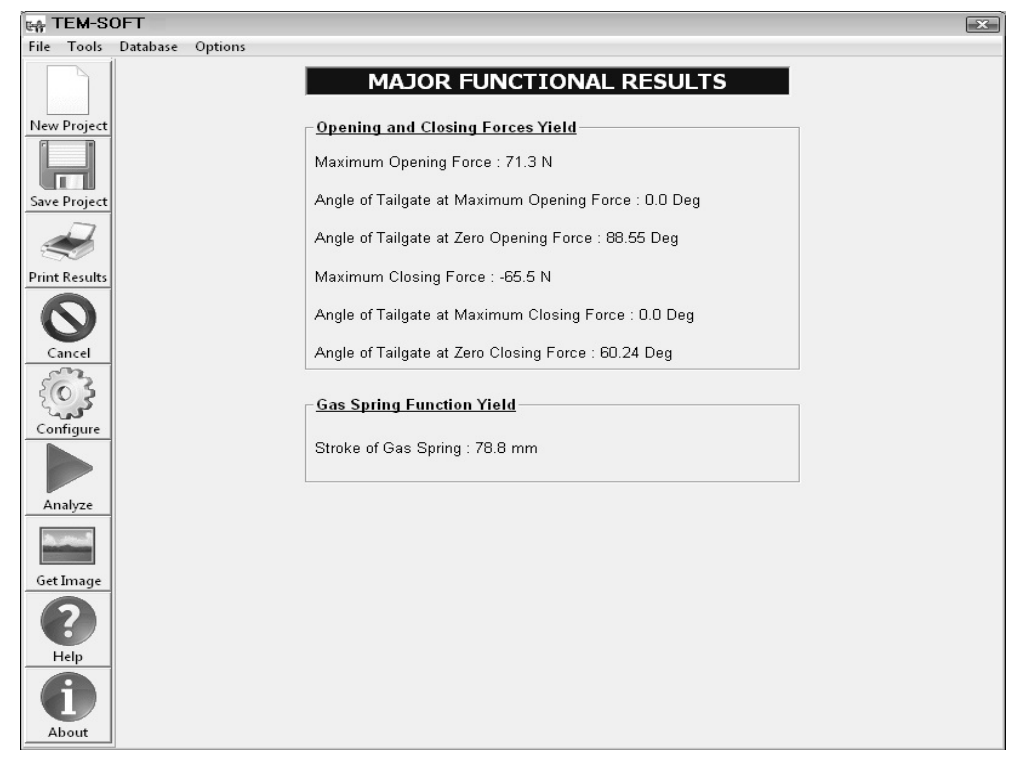

Figure 5. Major Functional Results interface of TEM-SOFT. 
the tailgate, closed and fully open positions, y-coordinates of the vehicle side (VSH) and tailgate side (TSH) hinges of the gas spring, the opening $(\mathrm{OH})$ and closing $(\mathrm{CH})$ handle locations, the friction intensity and the compression coefficient of the gas spring and the number of gas springs assembled to the tailgate are kept fixed throughout the study, where the corresponding values are shown in Table 1. As the impact of assembly scheme of the gas spring with the vehicle and tailgate are studied by varying the $\mathrm{x}$-coordinates of the hinges on both the vehicle (VSH) and tailgate (TSH) sides, 3 different mass centers are as well tested to identify the related variations. Besides, it is also aimed to work on the influences of gas spring type and the temperature conditions on the overall operational characteristics of the tailgate operation; thus the gas spring nominal force and the working temperature are assigned the values of $\mathrm{F}_{\mathrm{gs}-\mathrm{n}}=100,150,200 \mathrm{~N}$ and $\mathrm{T}=-10^{\circ} \mathrm{C}, 20^{\circ} \mathrm{C}, 50^{\circ} \mathrm{C}$ respectively. The structural alternatives of the assembly schemes (A, B and C), the component based and environmental data of the investigations are introduced through Table 2; moreover the closed $\left(\theta=0^{\circ}\right)$, fully open $\left(\theta=90^{\circ}\right)$ and mid-way $\left(\theta=45^{\circ}\right)$ position appearances of the complete tailgate-gas spring assemblies are demonstrated in Figure 6 for assembly schemes $\mathrm{A}$ and $\mathrm{C}$. The outputs of the numerical evaluations are displayed and discussed in terms of the variations of the weight moments, gas spring output forces, gas spring moments and the manual forces for different assembly schemes, tailgate mass centers, gas spring types and working temperatures in the complete angular operation range of the tailgate.

Figure 7 demonstrates the influence of the mass center location on the weight moment $\left(\mathrm{M}_{\mathrm{w}}\right)$. The primary determination from the plot comes out to be the elevating role of the distant mass centers $(T M C A \rightarrow C$ ) from the vehicle-tailgate

Table 1. Fixed parameters in the analysis.

\begin{tabular}{cccc}
\hline Length of Tailgate: & $600 \mathrm{~mm}$ & Weight of Tailgate: & $147.15 \mathrm{~N}$ \\
\hline Tailgate Closed Position: & $0^{\circ}$ & Tailgate Fully Open Position: & $90^{\circ}$ \\
GS TSH $\mathrm{y}_{\mathrm{y}}:$ & $-10 \mathrm{~mm}$ & GS VSH & $-50 \mathrm{~mm}$ \\
$\mathrm{OH}_{\mathbf{x}}:$ & $605 \mathrm{~mm}$ & $\mathrm{OH}_{\mathrm{y}}:$ & $0 \mathrm{~mm}$ \\
$\mathrm{CH}_{\mathbf{x}}:$ & $590 \mathrm{~mm}$ & $\mathrm{CH}_{\mathrm{y}}:$ & $-30 \mathrm{~mm}$ \\
Compression Coefficient: & 1.3 & GS Friction Force: & $80 \mathrm{~N}$ \\
Number of Gas Springs: & 2 & & \\
\hline
\end{tabular}

Table 2. Scenario alternatives in the analysis.

\begin{tabular}{ccccc}
\hline Type & Assembly Scheme & MassCenter & Gas Spring & Temperature \\
\hline \multirow{2}{*}{ A } & $\mathrm{GS} \mathrm{TSH}_{\mathrm{x}}=60 \mathrm{~mm}$ & $\mathrm{MC}_{\mathrm{x}}=300 \mathrm{~mm}$ & $\mathrm{~F}_{\mathrm{gs}-\mathrm{n}}=100 \mathrm{~N}$ & $\mathrm{~T}=-10^{\circ} \mathrm{C}$ \\
& $\mathrm{GS} \mathrm{VSH}_{\mathrm{x}}=155.5 \mathrm{~mm}$ & $\mathrm{MC}_{\mathrm{y}}=0 \mathrm{~mm}$ & & \\
B & $\mathrm{GS} \mathrm{TSH}_{\mathrm{x}}=120 \mathrm{~mm}$ & $\mathrm{MC}_{\mathrm{x}}=360 \mathrm{~mm}$ & $\mathrm{~F}$ & \\
& $\mathrm{GS} \mathrm{VSH}_{\mathrm{g}-\mathrm{n}}=293.1 \mathrm{~mm}$ & $\mathrm{MC}_{\mathrm{y}}=-80 \mathrm{~mm}$ & $\mathrm{~T}=20^{\circ} \mathrm{C}$ \\
$\mathrm{C}$ & $\mathrm{GS} \mathrm{TSH}_{\mathrm{x}}=180 \mathrm{~mm}$ & $\mathrm{MC}_{\mathrm{x}}=420 \mathrm{~mm}$ & $\mathrm{~F}_{\mathrm{gs}-\mathrm{n}}=200 \mathrm{~N}$ & $\mathrm{~T}=50^{\circ} \mathrm{C}$ \\
\hline
\end{tabular}



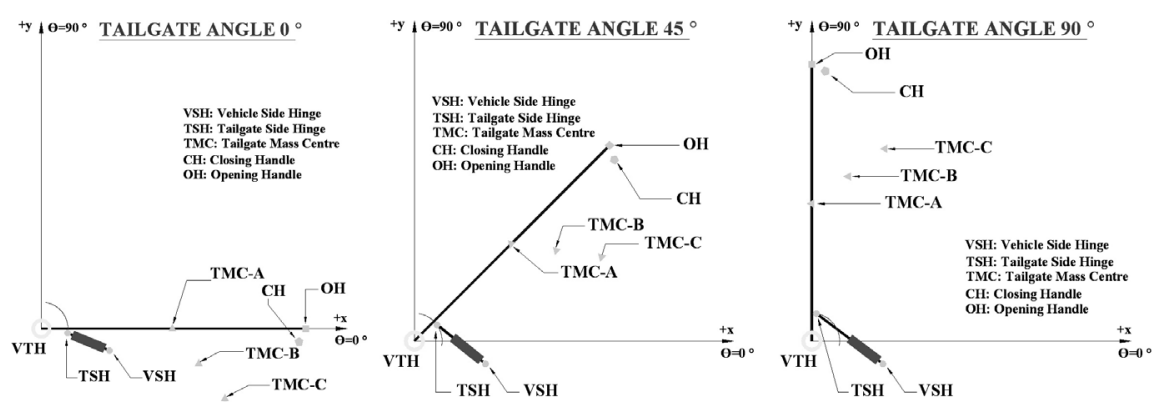

(a)
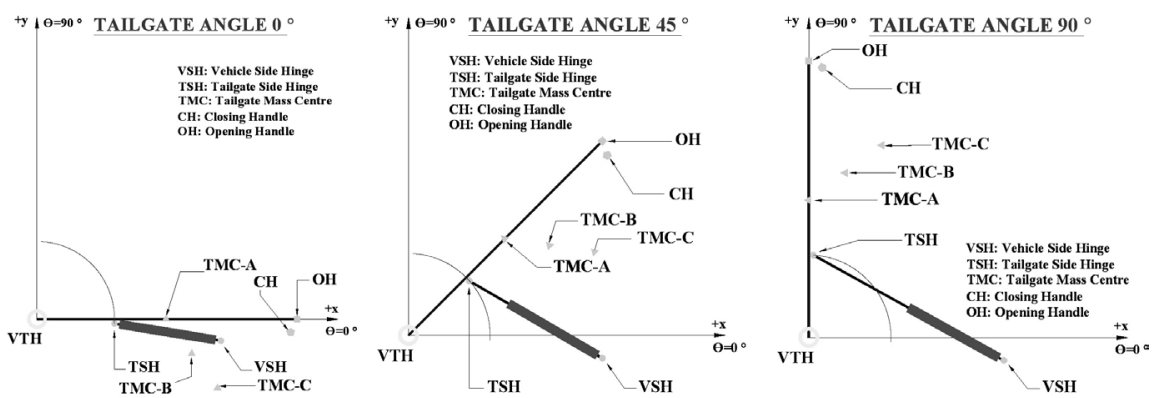

(b)

Figure 6. Schematic representation of tailgate-gas spring assembly; (a) Assembly scheme-A; (b) Assembly scheme-C.

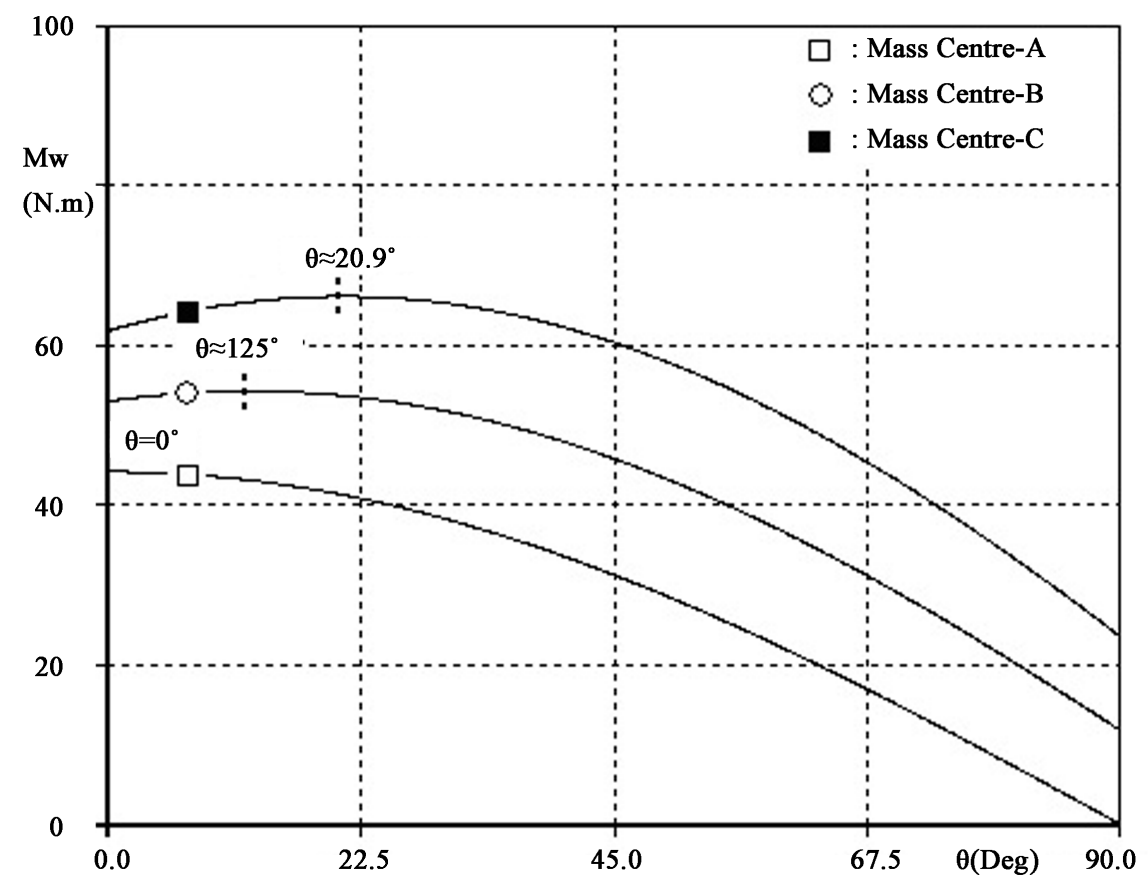

Figure 7. Variation of weight moments for different mass centers.

hinge on $\mathrm{M}_{\mathrm{w}}$. Besides, classifying the mass center locations, from the point of relative position with the tailgate body, result in distinct $\mathrm{M}_{\mathrm{w}}$ characteristics during the angular rotation of the tailgate. As mass center-A coincides with the tailgate body (Figure 6), the moment arm continuously decreases during the open- 
ing operation $\left(\theta=0^{\circ} \rightarrow 90^{\circ}\right)$, thus the $\mathrm{M}_{\mathrm{w}}$ values come out to be consistent with this physical fact. On the other hand, in scenarios with the mass center alternatives of $B$ \& $C$, augmentations in $M_{w}$ are evaluated at the initial stages of the opening operation. The growing attitude of $\mathrm{M}_{\mathrm{w}}$ with the rotation of the tailgate mainly depends on the so developing orientation of the longer perpendicular moment arm (Figure 6). Computations identified the maximum $\mathrm{M}_{\mathrm{w}}$ positions as $\theta \approx 12.5^{\circ}$ and $\theta \approx 20.9^{\circ}$ for the mass centers $B$ and $C$ respectively. The enhancement of $M_{w}$ is significant from the point of the probable compensating manual force level. It can be said that $\mathrm{M}_{\mathrm{w}}$ is deterministic on the manual force; however it must also be remembered that the selection of the appropriate gas spring stands as the chief design focus, based on both mechanic and ergonomic considerations.

Figure 8 displays the variation of the gas spring output force $\left(\mathrm{F}_{\mathrm{gs}-\mathrm{o}}\right)$ with tailgate position angle $(\theta)$ during the closing and opening operations of the tailgate, for 3 gas spring types and working temperatures. It can be inspected from the figure that, in both opening and closing operations, $\mathrm{F}_{\mathrm{gs}-\mathrm{o}}$ increases with temperature. The descriptive measure of $F_{g s-o}$ is associated with the fully open position of the gas spring; however as can also be seen from the plot, stronger gas spring selection exhibits higher gas spring output forces in the entire operation route of the tailgate $\left(\theta=0^{\circ} \rightarrow 90^{\circ}\right)$. The variation in the output force mainly depends on the gas spring length $\left(\zeta_{\mathrm{gs}}\right)$, manipulating the internal pressure level, but on the direction of the friction as well. As the gas spring becomes shorter, the internal pressure, thus the output force, rises, where the contrary structural variation decreases the output force. The evaluations on the continuous increase and decline of the gas spring output force can be clarified depending on this engineering phenomenon. Comparing the numerical values at the critical phases of the tailgate operation for different gas spring types and temperature levels enlighten the individual and combined roles of the acting parameters more clearly. Such that as the $\left(\mathrm{F}_{\mathrm{gs}-\mathrm{o}}\right)_{\theta=0^{\circ}} /\left(\mathrm{F}_{\mathrm{gs}-\mathrm{o}}\right)_{\theta=90^{\circ}} \quad$ ratio offers the values of $(3.76 \rightarrow 1.16) \quad \mathrm{T}=\mathrm{T}_{\mathrm{A}}$ and $(2.09 \rightarrow 1.17) \quad \mathrm{T}=\mathrm{T}_{\mathrm{C}}$ (opening $\rightarrow$ closing) for gas spring type-A, they become $(1.54 \rightarrow 1.21) \quad \mathrm{T}=\mathrm{T}_{\mathrm{A}}$ and $(1.47 \rightarrow 1.22) \quad \mathrm{T}=\mathrm{T}_{\mathrm{C}}$ with stronger gas spring (Type-C). These values put forward that the influence of working temperature is more influential in weaker gas spring types and becomes more pronounced during opening. On the other hand, the role of temperature can be most critical

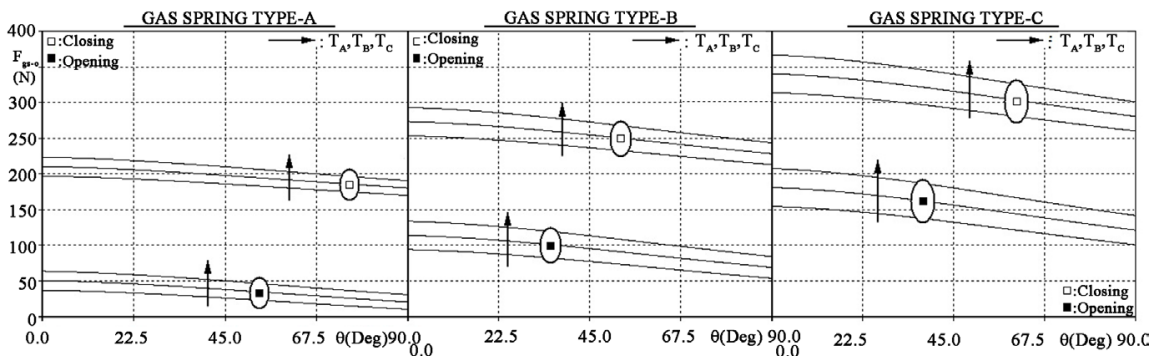

Figure 8. Variation of gas spring output force for different gas spring types and working temperatures. 
at the onset and final positions of the tailgate operations. To clarify this phenomena $\left(\mathrm{F}_{\text {gs-o }}\right)_{\mathrm{T}=\mathrm{T}_{\mathrm{C}}} /\left(\mathrm{F}_{\text {gs-o }}\right)_{\mathrm{T}=\mathrm{T}_{\mathrm{A}}}$ is evaluated as $(1.73 \rightarrow 1.14) \quad \theta=0^{\circ}$ and

$(3.10 \rightarrow 1.12) \quad \theta=90^{\circ}$ for gas spring type-A and $(1.35 \rightarrow 1.17) \quad \theta=0^{\circ}$ and $(1.41 \rightarrow 1.16) \quad \theta=90^{\circ}$ for gas spring type-C. These values are in harmony with the above comparisons from the point of the comparably more pronounced impact of temperature on weaker gas spring type and during opening. They further imply that the output force is more remarkably influenced by temperature at the fully open instant $\left(\theta=90^{\circ}\right)$ during opening; however the ratios for closing appear in the narrow band of $1.12-1.17$ at the closed $\left(\theta=0^{\circ}\right)$ and fully open positions. As defined by Equation (5) the friction force of the gas spring is one of the deterministic parameters on the deviation of the opening and closing forces. Developing the contributing analogy of $\left(\mathrm{F}_{\mathrm{gs}-\mathrm{o}}\right)_{\mathrm{cl}} /\left(\mathrm{F}_{\mathrm{gs}-\mathrm{o}}\right)_{\mathrm{op}}$ for gas spring types $\mathrm{A} \rightarrow \mathrm{C}$ generates the data of $(5.36 \rightarrow 2.04) \quad \mathrm{T}=\mathrm{T}_{\mathrm{A}}$ and $(3.53 \rightarrow 1.77) \quad \mathrm{T}=\mathrm{T}_{\mathrm{C}}$

for the closed tailgate position of $\theta=0^{\circ}$ and $(17.39 \rightarrow 2.61) \quad \mathrm{T}=\mathrm{T}_{\mathrm{A}}$ and $(6.29 \rightarrow 2.14) \quad \mathrm{T}=\mathrm{T}_{\mathrm{C}}$ for the fully open tailgate position of $\theta=90^{\circ}$. The more particular gaps among the closing and opening forces appear in the weaker gas spring application (Type-A) and with lower operation temperature $\left(T=T_{A}\right)$. The basics of this outcome can be detailed by 2 facts: 1 ) The level of the friction is mostly characterized by the interior force transmitting structure of the gas spring and do not vary with the nominal force $\left(\mathrm{F}_{\mathrm{gs}-\mathrm{n}}\right)$ or working temperature (T). 2) The dependence of the $\mathrm{F}_{\mathrm{gs}-\mathrm{n}}$ on the gas spring type and working temperature is decisive on the above ratios; lower $\mathrm{F}_{\mathrm{gs}-\mathrm{n}}$ causes more remarkable friction influence on the gap of the closing and opening forces.

Variation of gas spring moments $\left(\mathrm{M}_{\mathrm{gs}}\right)$ with tailgate position angle $(\theta)$ during the opening and closing operations for 3 assembly schemes and working temperatures and for 2 gas spring types are shown in Figure 9. In the complete set of the scenarios considered, the $\mathrm{M}_{\mathrm{gs}}$ are in counterclockwise (CC) direction (Equation (8)); thus get the minus sign. As displayed and discussed through Figure 8, the $\mathrm{F}_{\mathrm{gs}-\mathrm{o}}$ values continuously decrease in the opening direction $\left(\theta=0^{\circ} \rightarrow 90^{\circ}\right)$; however the $\mathrm{M}_{\mathrm{gs}}$ exhibit rather a varying trend. The initial ascends in CC direction up to the maximum value $\left(\mathrm{M}_{\mathrm{gs}-\max }\right)$ are due to the elongation of the moment arm; the following descends depend on the so occurring shorter moment arm orientation with rotation (Figure 6). Computations indicated the angular positions of the maximum gas spring moments $\left((\theta)_{\mathrm{M}_{\mathrm{gs-max}}}\right)$ as $\left(34.9^{\circ} \rightarrow 40.1^{\circ}\right)_{\mathrm{GS} \text { Type-A }}$ and $\left(45.4^{\circ} \rightarrow 46.4^{\circ}\right)_{\mathrm{GS} \text { Type-C }}\left(\mathrm{T}=\mathrm{T}_{\mathrm{A}} \rightarrow \mathrm{T}_{\mathrm{C}}\right)$ for assembly scheme- $\mathrm{A},\left(37.2^{\circ} \rightarrow 42.0^{\circ}\right)_{\mathrm{GS} \text { Type-A }}$ and $\left(47.2^{\circ} \rightarrow 48.2^{\circ}\right)_{\mathrm{GS} \text { Type-C }}$ for assembly scheme-C during opening; whereas during closing these positions become $\left(53.8^{\circ} \rightarrow 53.4^{\circ}\right)_{\mathrm{GS} \text { Type-A }}$ and $\left(52.3^{\circ} \rightarrow 51.9^{\circ}\right)_{\mathrm{GS} \text { Type-C }}$ for assembly scheme-A, $\left(55.6^{\circ} \rightarrow 55.1^{\circ}\right)_{\mathrm{GS} \text { Type-A }}$ and $\left(54.1^{\circ} \rightarrow 53.7^{\circ}\right)_{\mathrm{GS} \text { Type-C }}$ for assembly scheme-C. These evaluations reveal that the $(\theta)_{\mathrm{M}_{\mathrm{gs}-\mathrm{max}}}$ shifts in the direction of the tailgate rotation with stronger $\mathrm{F}_{\mathrm{gs-o}}$ both in opening and closing operations; moreover the ascertained impact is more sensible during opening. 


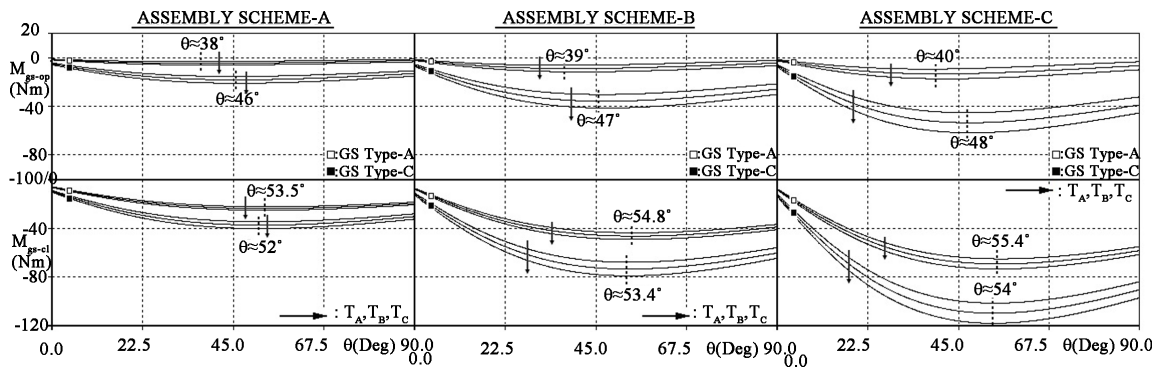

Figure 9. Variation of gas spring moments for different gas spring types, assembly schemes and working temperatures.

Besides, gas spring type and working temperature cause similar consequences on $\mathrm{M}_{\mathrm{gs}}$ (Figure 9) as on $\mathrm{F}_{\mathrm{gs}-\mathrm{o}}$ (Figure 8); more explicitly defining outlines that with stronger gas spring (Type-C) and higher temperature $\left(\mathrm{T}_{\mathrm{C}}\right.$ ), more potentially behaving $\mathrm{M}_{\mathrm{gs}}$ are exposed. The superior nature of the closing gas spring moments $\left(\mathrm{M}_{\mathrm{gsccl}}\right)$ to those of the opening $\left(\mathrm{M}_{\mathrm{gs}-\mathrm{p}}\right)$ can directly be attributed to the friction of the gas spring, which as well created the identical affect on the $\mathrm{F}_{\text {gs-o }}$ (Figure 8). On the other hand, the performed analyses shown that the impact of assembly scheme on $\mathrm{M}_{\mathrm{gs}}$ is dependent on the angular position, whereas independent from the type of operation and gas spring and the level of working temperature as well. More specific reporting offers the $\left(\mathrm{M}_{\mathrm{gs}}\right)_{\mathrm{AS}-\mathrm{C}} /\left(\mathrm{M}_{\mathrm{gs}}\right)_{\mathrm{AS}-\mathrm{A}}$ ratios of 1.36, 2.95 and 3.01 at the angular positions of $\theta=0^{\circ},(\theta)_{\mathrm{M}_{\mathrm{gs}-\max }}$ and $90^{\circ}$ respectively.

Figure 9 further demonstrates the magnitude of $\mathrm{M}_{\mathrm{gs}}$ variation during tailgate operation. Comparing the $\mathrm{M}_{\mathrm{gs}}$ values of the closed $\left(\theta=0^{\circ}\right)$, fully open $\left(\theta=90^{\circ}\right)$ and $\mathrm{M}_{\mathrm{gs}-\max }$ generates the tabulated data of Table 3. The records identify that the assembly scheme design has potential to encourage the $M_{g s}$ values both in opening and closing; moreover higher temperature $\left(\mathrm{T}=\mathrm{T}_{\mathrm{C}}\right)$ and stronger gas spring (Type-C) progresses the scale of $\mathrm{M}_{\mathrm{gs}}$ only in opening scenarios. More precise denoting brings forth the $\left(\mathrm{M}_{\mathrm{gs}}\right)_{\theta=90^{\circ}} /\left(\mathrm{M}_{\mathrm{gs}}\right)_{\theta=0^{\circ}}$ ratios of $(1.03 \rightarrow 1.86)_{\mathrm{GS} \text { Type-A }}$ and $(2.52 \rightarrow 2.64)_{\mathrm{GS} \text { Type-C }}\left(\mathrm{T}=\mathrm{T}_{\mathrm{A}} \rightarrow \mathrm{T}_{\mathrm{C}}\right)$ in assembly scheme-A and $(2.30 \rightarrow 4.13)_{\text {GS Type-A }}$ and $(5.61 \rightarrow 5.87)_{\mathrm{GS}}$ Type-C in assembly scheme-C during opening (Table 3(a)); these values rise to $(3.36 \rightarrow 3.31)_{\mathrm{GS}}$ Type-A $_{\mathrm{A}}$ and $(3.22 \rightarrow 3.19)_{\mathrm{GS}}$ Type-C in assembly scheme-A and $(7.46 \rightarrow 7.36)_{\text {GS Type-A }}$ and $(7.15 \rightarrow 7.08)_{\text {GS Type-C }}$ in assembly scheme-C during closing (Table 3(b)). Table 3 further shows that the maximum gas spring moment values $\left(\mathrm{M}_{\mathrm{gs}-\max }\right)$ become more provoked with temperature, strong gas spring and assembly scheme during opening; however only with assembly scheme during closing.

Due to the significance in identifying the success of the overall design of the tailgate mechanism, computation of the manual force $\left(\mathrm{F}_{\text {man }}\right)$ in the physical operation range $\left(\theta=0^{\circ}-90^{\circ}\right)$ is considered as the key issue. Figure 10 displays the variation of $\mathrm{F}_{\operatorname{man}}$ with tailgate angular position for different gas spring types, working temperatures, mass centers and assembly schemes during the opening and closing operations. As the principle ergonomic design criteria in tailgate operation is to satisfy the $\mathrm{F}_{\operatorname{man}}=0$ condition at the appropriate angular position, 
Table 3. (a) Gas spring moment comparison table for opening operation; (b) Gas spring moment comparison table for closing operation.

(a)

\begin{tabular}{ccccccccc}
\hline & \multicolumn{3}{c}{ Assembly Scheme-A } & \multicolumn{3}{c}{ Assembly Scheme-C } \\
\cline { 2 - 10 } & \multicolumn{2}{c}{ GS Type-A } & \multicolumn{2}{c}{ GS Type-C } & \multicolumn{2}{c}{ GS Type-A } & \multicolumn{2}{c}{ GS Type-C } \\
\cline { 2 - 10 } & $\mathrm{T}_{\mathrm{A}}$ & $\mathrm{T}_{\mathrm{C}}$ & $\mathrm{T}_{\mathrm{A}}$ & $\mathrm{T}_{\mathrm{C}}$ & $\mathrm{T}_{\mathrm{A}}$ & $\mathrm{T}_{\mathrm{C}}$ & $\mathrm{T}_{\mathrm{A}}$ & $\mathrm{T}_{\mathrm{C}}$ \\
\hline$\left(\mathrm{M}_{\mathrm{gs}}\right)_{\theta=90} /\left(\mathrm{M}_{\mathrm{gs}}\right)_{\theta=0} \cdot$ & 1.03 & 1.86 & 2.52 & 2.64 & 2.30 & 4.13 & 5.61 & 5.87 \\
$\mathbf{M}_{\mathrm{gs}-\max } /\left(\mathrm{M}_{\mathrm{gs}}\right)_{\theta=0} \cdot$ & 3.07 & 3.34 & 3.61 & 3.67 & 6.69 & 7.27 & 7.87 & 7.99 \\
\hline
\end{tabular}

(b)

\begin{tabular}{cccccccccc}
\hline & \multicolumn{3}{c}{ Assembly Scheme-A } & \multicolumn{3}{c}{ Assembly Scheme-C } \\
\cline { 2 - 9 } & \multicolumn{3}{c}{ GS Type-A } & \multicolumn{2}{c}{ GS Type-C } & \multicolumn{2}{c}{ GS Type-A } & \multicolumn{2}{c}{ GS Type-C } \\
\cline { 2 - 10 } & $\mathrm{T}_{\mathrm{A}}$ & $\mathrm{T}_{\mathrm{C}}$ & $\mathrm{T}_{\mathrm{A}}$ & $\mathrm{T}_{\mathrm{C}}$ & $\mathrm{T}_{\mathrm{A}}$ & $\mathrm{T}_{\mathrm{C}}$ & $\mathrm{T}_{\mathrm{A}}$ & $\mathrm{T}_{\mathrm{C}}$ \\
\hline$\left(\mathrm{M}_{\mathrm{gs}}\right)_{\theta=90^{\circ}} /\left(\mathrm{M}_{\mathrm{gs}}\right)_{\theta=0} \cdot$ & 3.36 & 3.31 & 3.22 & 3.19 & 7.46 & 7.36 & 7.15 & 7.08 \\
$\mathrm{M}_{\mathrm{gs}-\max } /\left(\mathrm{M}_{\mathrm{gs}}\right)_{\theta=0}{ }^{\circ}$ & 4.04 & 4.02 & 3.97 & 3.95 & 8.83 & 8.77 & 8.65 & 8.61 \\
\hline
\end{tabular}

comparisons among the alternative constructive designs and component selections need to be discussed comprehensively. Figure 10 demonstrates that the level of working temperature and the location of the mass center generates contrary consequences on $\mathrm{F}_{\operatorname{man}}$ during opening and closing operations. As discussed through Figure 7, moving the mass center away $(A \rightarrow C)$ from the vehicle-tailgate hinge causes the $M_{w}$ values to advance. This phenomena results in the need for stronger $\mathrm{F}_{\operatorname{man}}$ during opening; however the opposite while closing the tailgate. Similarly, the encouraged $\mathrm{F}_{\mathrm{gs}-\mathrm{o}}$ values with temperature (Figure 8) support the purpose of $F_{\operatorname{man}}$ during opening; however the resistive-action opposing the $F_{\operatorname{man}}$ in the closing phase gives rise to the necessity in the grow of $\mathrm{F}_{\text {man }}$ with temperature. Figure 10 further displays that, being independent of mass center, working temperature and assembly scheme, stronger gas spring (Type-C) selection result in lower $\mathrm{F}_{\operatorname{man}}$ while opening and higher $\mathrm{F}_{\operatorname{man}}$ during the closing operations of the tailgate. The impact of GS-Type is most remarkable at the fully open position $\left(\theta=90^{\circ}\right)$ where the $\left(\mathrm{F}_{\text {man GS Type-A }} / \mathrm{F}_{\text {man GS Type-C }}\right)_{\theta=90^{\circ}}$ ratio is evaluated in the assembly scheme-A (Figure 10(a)) as $0.10 \rightarrow 0.22\left(\mathrm{~T}=\mathrm{T}_{\mathrm{A}} \rightarrow \mathrm{T}_{\mathrm{C}}\right)$ for mass center-A and $1.76 \rightarrow 2.42$ for mass center- $\mathrm{C}$ during opening and $0.65 \rightarrow 0.63$ for mass center- $\mathrm{A}$ and $-1.18 \rightarrow-0.34$ for mass center- $\mathrm{C}$ during closing. These proportions become $0.10 \rightarrow 0.22$ and $-2.31 \rightarrow-0.62$ for mass centers $-\mathrm{A}$ and $-\mathrm{C}$ during opening and $0.65 \rightarrow 0.63$ and $0.52 \rightarrow 0.52$ for mass centers $-A$ and $-\mathrm{C}$ in the closing operation of assembly scheme-C (Figure 10(b)). These numbers identify that the influence of the nominal force specification of the gas spring on the manual force depends primarily on the type of the assembly scheme, secondarily on the mass center location and to some extent on the working temperature. The identical ratios in either of the assembly schemes (A and C) for mass center-A reveal the fact that the structural design of the tailgate mechanism has no additional impact on the variation of $\mathrm{F}_{\operatorname{man}}$ with gas spring at $\theta=90^{\circ}$. This outcome for mass center-A can 


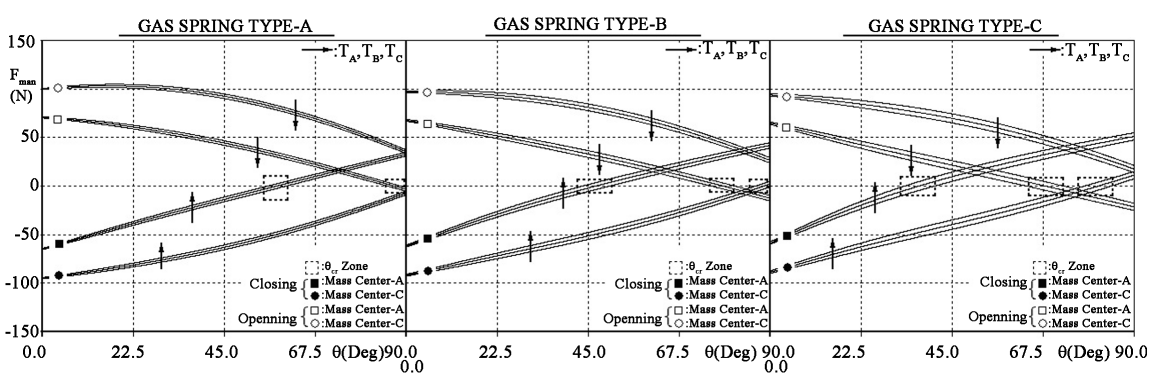

(a)

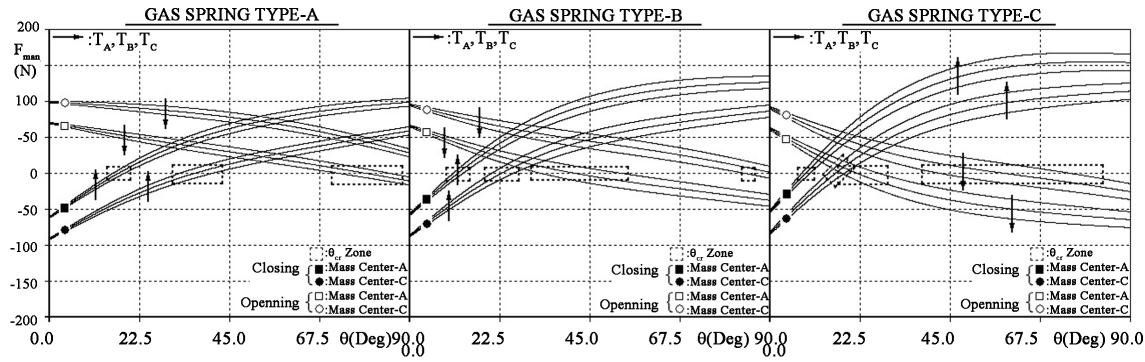

(b)

Figure 10. Variation of manual forces with (a) Assembly scheme-A and (b) Assembly scheme-C for different gas spring types, mass centers and working temperatures.

Table 4. Critical position angles of the tailgate.

\begin{tabular}{cccccc}
\hline & & \multicolumn{2}{c}{ Assembly Scheme-A } & \multicolumn{2}{c}{ Assembly Scheme-C } \\
\cline { 3 - 6 } & & Mass Center-A & Mass Center-C & Mass Center-A & Mass Center-C \\
\cline { 3 - 6 } & & $\mathrm{T}=\mathrm{T}_{\mathrm{A}} \rightarrow \mathrm{T}_{\mathrm{C}}$ & $\mathrm{T}=\mathrm{T}_{\mathrm{A}} \rightarrow \mathrm{T}_{\mathrm{C}}$ & $\mathrm{T}=\mathrm{T}_{\mathrm{A}} \rightarrow \mathrm{T}_{\mathrm{C}}$ & $\mathrm{T}=\mathrm{T}_{\mathrm{A}} \rightarrow \mathrm{T}_{\mathrm{C}}$ \\
\hline \multirow{2}{*}{ Opening } & GS Type-A & $88.6^{\circ} \rightarrow 85.3^{\circ}$ & $-\rightarrow-$ & $84.9^{\circ} \rightarrow 72.2^{\circ}$ & $-\rightarrow-$ \\
& GS Type-C & $72.5^{\circ} \rightarrow 63.4^{\circ}$ & $-\rightarrow-$ & $27.2^{\circ} \rightarrow 17.9^{\circ}$ & $74.9^{\circ} \rightarrow 42.3^{\circ}$ \\
\cline { 3 - 6 } Closing & GS Type-A & $60.2^{\circ} \rightarrow 55.7^{\circ}$ & $-\rightarrow-$ & $18.7^{\circ} \rightarrow 15.8^{\circ}$ & $40.7^{\circ} \rightarrow 32.6^{\circ}$ \\
& GS Type-C & $40.7^{\circ} \rightarrow 33.2^{\circ}$ & $84.3^{\circ} \rightarrow 77.7^{\circ}$ & $10.0^{\circ} \rightarrow 7.9^{\circ}$ & $18.5^{\circ} \rightarrow 14.6^{\circ}$ \\
\hline
\end{tabular}

be clarified by 3 interconnected concepts: 1) Mass center-A is located inside the tailgate body thus the weight vector is coaxial with vehicle-tailgate hinge (VTH) at $\left.\theta=90^{\circ}, 2\right)$ The weight moment of the tailgate vanishes at $\theta=90^{\circ}$

$\left(M_{w}=0\right.$-Figure 7$)$, thus the only moment to be balanced by $F_{m a n}$ is that of the gas spring $\left(\mathrm{M}_{\mathrm{gs}}\right.$-Figure 9), 3) Since the moment arms of $\mathrm{F}_{\mathrm{man}}$ are fixed (Table 1 ), the growing rates of the gas spring moments are exactly reflected to the applied manual forces. Moreover, it should be inspected from the above ratios that numerically comparing the manual forces with reverse direction results in the (-) signs, which as well puts forward the additional need in deeper discussion from the ergonomic point of view. Figure 10 further enlightens the $F_{\operatorname{man}}=0$ positions as $\theta_{\text {cr }}$ zones in conjunction with the working temperature range, being the most decisive information from the point of ergonomic design considerations. As presented in Table 4 all the scenarios considered in the analysis are not capable of possessing the $\mathrm{F}_{\operatorname{man}}=0$ condition in the opening and closing phases; indeed 
this fact is as well the fundamental source of the negative

$\left(\mathrm{F}_{\text {man GS Type-A }} / \mathrm{F}_{\text {man GS Type-C }}\right)_{\theta=90^{\circ}}$ ratios defined above. It can be inspected from the table that assembly scheme-A appears not to be eligible in satisfying this ergonomic necessity especially with distant mass center $(C)$ possibilities. Moreover, the $\theta_{\mathrm{cr}}\left(\mathrm{F}_{\mathrm{man}}=0\right)$ positions of $88.6^{\circ} \rightarrow 85.3^{\circ}\left(\mathrm{T}=\mathrm{T}_{\mathrm{A}} \rightarrow \mathrm{T}_{\mathrm{C}}\right)$ for gas spring type-A and $72.5^{\circ} \rightarrow 63.4^{\circ}$ for gas spring type- $\mathrm{C}$ can be considered as late tasks of assembly scheme-A for opening. Besides the corresponding $\theta_{\text {cr }}$ positions for closing are evaluated as $60.2^{\circ} \rightarrow 55.7^{\circ}$ and $40.7^{\circ} \rightarrow 33.2^{\circ}$, which can be regarded as early phases of operation, probably causing undesirable acceleration of the tailgate before locking. On the other hand, designing the tailgate structure with assembly scheme-C modifies the $\mathrm{F}_{\mathrm{man}}=0$ positions to $\theta_{\mathrm{cr}}=84.9^{\circ} \rightarrow 72.2^{\circ}$, in the case with mass center- $\mathrm{A}$ for gas spring type-A and $27.2^{\circ} \rightarrow 17.9^{\circ}$ for gas spring type-C during opening and to $18.7^{\circ} \rightarrow 15.8^{\circ}$ and $10.0^{\circ} \rightarrow 7.9^{\circ}$ while closing. These positions identify the appropriateness of the combined-form of gas spring type-A and assembly scheme-C for tailgate design with mass center-A. However, the investigations on the structural model with the shifted mass center $(\mathrm{C})$ bring about the appropriate $\theta_{\text {cr }}$ positions of $74.9^{\circ} \rightarrow 42.3^{\circ}$ for opening and $18.5^{\circ} \rightarrow 14.6^{\circ}$ for closing with the gas spring type-C. This record reveals not only the significance of the gas spring selection in conjunction with the complete set of structural design and operating parameters but also the fact that the distance between the mass center and the vehicle-tailgate hinge is the most prominent parameter defining the specification on the nominal force level of the gas spring that is to be assembled to the tailgate system.

The overview of the discussions on $\mathrm{F}_{\operatorname{man}}=0$ positions indicate that stronger gas springs (Type-C) shift the $\theta_{\text {cr }}$ closer to the initial phases of the opening operation. Although this outcome creates the feeling of a design success, the accompanying need on a superior initial manual force during closing $\left(\mathrm{F}_{\operatorname{man}-\theta=90^{\circ}}\right)$ can also be declared as a design incompetence from the point of ergonomic expectations.

\section{Conclusions}

The present paper has introduced the new visual academic software TEM-SOFT and discussed the results of the comprehensive numerical investigations on the gas spring integrated tailgate operation with the complete set of geometric, component based and operational parameters. The major findings can be summarized as follows: In tailgate designs with mass centers outside the solid domain, the growing attitude of $\mathrm{M}_{\mathrm{w}}$ at the initial stages of opening operation mainly depends on the so developing orientation of the longer perpendicular moment arm. The working temperature is more influential on the output force values of weaker gas spring types and becomes more pronounced during opening. Both in opening and closing operations the $(\theta)_{\mathrm{M}_{\mathrm{gs}-\max }}$ position shifts in the direction of the tailgate rotation with stronger $\mathrm{F}_{\mathrm{gs}-\mathrm{o}}$; moreover this impact is more remarkable during opening. The distance between the mass center and the ve- 
hicle-tailgate hinge is the most prominent parameter defining the specification on the nominal force level of the gas spring that is to be assembled to the tailgate system. Besides, the gas spring selection, in conjunction with the complete set of structural design and operating parameters, is as well determinative on the manual force level. Stronger gas springs shift the $\theta_{\text {cr }}$ closer to the initial phases of the opening operation. Although this outcome creates the feeling of a design success, the accompanying need on a superior initial manual force during closing $\left(\mathrm{F}_{\operatorname{man}-\theta=90^{\circ}}\right)$ can also be declared as a design incompetence from the point of ergonomic expectations.

As future work, investigation of multi-link mechanisms for the tailgate operation will be essential. Four-bar or six-bar mechanisms find usage in vehicle tailgate design and they enable greater movement opposed to simple hinge design which is presented in this study. Additionally, the analysis of kinematics and synthesis of these mechanisms should be embedded into the software.

\section{Conflicts of Interest}

The authors declare no conflicts of interest regarding the publication of this paper.

\section{References}

[1] Komatsu, T., Komeda, T. and Uchida, T. (1999) Development of a Safety Mechanism Using a Gas Spring. Advanced Robotics, 13, 309-310. https://doi.org/10.1163/156855399X01477

[2] Stabilus. Gas Springs and Dampers for Medical Technology and Rehab Applications.

[3] Pham, H.T. and Wang, D.A. (2011) A Constant-Force Bistable Mechanism for Force Regulation and Overload Protection. Mechanism and Machine Theory, 46, 899-909. https://doi.org/10.1016/j.mechmachtheory.2011.02.008

[4] Marcus, M., Gerr, F. and Monteilh, C. (2002) A Prospective Study of Computer Users: II. Postural Risk Factors for Musculoskeletal Symptoms and Disorders. American Journal of Industrial Medicine, 41, 236-249. https://doi.org/10.1002/ajim.10067

[5] Mukhopadhyay, P., O’Sullivan, L.W. and Gallwey, T.J. (2009) Upper Limb Discomfort Profile Due to Intermittent Isometric Pronation Torque at Different Postural Combinations of the Shoulder-Arm System. Ergonomics, 52, 584-600. https://doi.org/10.1080/00140130802396438

[6] de Groot, J.H. and Brand, R. (2001) A Three-Dimensional Regression Model of the Shoulder Rhythm. Clinical Biomechanics, 16, 735-743. https://doi.org/10.1016/S0268-0033(01)00065-1

[7] Cort, J.A. and Potvin, J.R. (2011) Maximum Isometric Finger Pull Forces. International Journal Industrial Ergonomics, 41, 91-95. https://doi.org/10.1016/j.ergon.2010.12.008

[8] Lin, J.H., Radwin, R.G. and Nembhard, D.A. (2005) Ergonomics Applications of a Mechanical Model of the Human Operator in Power Hand Tool Operation. Journal of Occupational and Environmental Hygiene, 2, 111-119. https://doi.org/10.1080/15459620590913155

[9] Hoozemans, M.J.M., Slaghuis, W., Faber, G.S. and van Dieën, J.H. (2007) Cart 
Pushing: The Effects of Magnitude and Direction of the Exerted Push force, and of Trunk Inclination on Low Back Loading. International Journal of Industrial Ergonomics, 37, 832-844. https://doi.org/10.1016/j.ergon.2007.07.013

[10] Laring, J., Forsman, M., Kadefors, R. and Örtengren, R. (2002) MTM-Based Ergonomic Workload Analysis. International Journal of Industrial Ergonomics, 30, 135-148. https://doi.org/10.1016/S0169-8141(02)00091-4

[11] Duprey, S., Savonnet, L., Black, N. and Wang, X. (2015) Muscle Force Prediction: Can We Rely on Musculoskeletal Model Estimations? A Case Study on Push Force Exertions with the Upper Limb. Computer Methods in Biomechanics and Biomedical Engineering, 18, 1934-1935. https://doi.org/10.1080/10255842.2015.1069575

[12] Reuding, T. and Meil, P. (2004) Predictive Value of Assessing Vehicle Interior Design Ergonomics in a Virtual Environment. Journal of Computing and Information Science in Engineering, 4, 109-113. https://doi.org/10.1115/1.1710867

[13] Moonki, J., Hyundeok, C. and Taehwan, R. (2009) Integrated Framework for Vehicle Interior Design Using Digital Human Model. Journal of Computer Science and Technology, 24, 1149-1161. https://doi.org/10.1007/s11390-009-9287-3

[14] Abidi, M. H., El-Tamimi, A.M., Al-Ahmari, A.M., Darwish, S.M. and Rasheed, M.S. (2013) Virtual Ergonomic Assessment of First Saudi Arabian Designed Car in a Semi-Immersive Environment. Procedia Engineering, 64, 622-631.

https://doi.org/10.1016/j.proeng.2013.09.137

[15] Lämkull, D., Hanson, L. and Örtengren, R. (2007) The Influence of Virtual Human Model Appearance on Visual Ergonomics Posture Evaluation. Applied Ergonomics, 38, 713-722. https://doi.org/10.1016/j.apergo.2006.12.007

[16] Joung, Y.-K., Li, Q. and Noh, S.D. (2016) XML-Based Neutral Schema for Automated Ergonomic Analysis with Digital Human Simulation and Inline Motion Capture. International Journal of Computer Integrated Manufacturing, 29, 25-41.

[17] Fritzsche, L. (2010) Ergonomics Risk Assessment with Digital Human Models in Car Assembly: Simulation versus Real Life. Human Factors and Ergonomics in Manufacturing \& Service Industries, 20, 287-299. https://doi.org/10.1002/hfm.20221

[18] Gilad, I. and Byran, E. (2015) Quantifying Driver'S Field-of-View in Tractors: Methodology and Case Study. International Journal of Occupational Safety and Ergonomics, 21, 20-29. https://doi.org/10.1080/10803548.2015.1017942

[19] Busemann, S., Steffen, J. and Herrmann, E. (2016) Interactive Planning of Manual Assembly Operations: From Language to Motion. Procedia CIRP, 41, 224-229. https://doi.org/10.1016/j.procir.2015.12.106

[20] Mårdberg, P., Yan, Y., Bohlin, R., Delfs, N., Gustafsson, S. and Carlson, J.S. (2016) Controller Hierarchies for Efficient Virtual Ergonomic Assessments of Manual Assembly Sequences. Procedia CIRP, 44, 435-440. https://doi.org/10.1016/j.procir.2016.02.084

[21] Wilder, D., Magnusson, M.L. and Fenwick, J. (1994) The Effect of Posture and Seat Suspension Design on Discomfort and Back Muscle Fatigue during Simulated Truck Driving. Applied Ergonomics, 25, 66-76. https://doi.org/10.1016/0003-6870(94)90067-1

[22] Pohl, S.E. and Ferrari, C. (2007) Comparison of Gas Spring Designs with Adjustable Spring Characteristic for a Free-Piston Engine. Forschung im Ingenieurwesen, 71, 181-188. https://doi.org/10.1007/s10010-007-0056-6

[23] Cho, I., Beak, I. and Jo, J. (2010) Lubrication Characteristics of Dual Piston Ring in Bent-Axis Type Piston Pumps. Journal of Mechanical Science and Technology, 24, 
1363-1368. https://doi.org/10.1007/s12206-010-0342-3

[24] Pereira, E.L.L. and Deschamps, C.J. (2011) Influence of Piston on Effectiveareas of Reed-Type Valves of Small Reciprocating Compressors. HVAC\&R Research, 17, 218-230. https://doi.org/10.1080/10789669.2011.566463

[25] Kornhauser, A.A. (1994) Dynamic Modeling of Gas Springs. Journal of Dynamic Systems, Measurement, and Control, 116, 414-418. https://doi.org/10.1115/1.2899236

[26] Mirels, H. (1994) Effect of Orifice Flow and Heat-Transfer on Gas Spring Hysteresis. AIAA Journal, 32, 1656-1661. https://doi.org/10.2514/3.12156

[27] Kornhauser, A.A. and Smith, J.L. (1993) The Effects of Heat-Transfer on Gas Spring Performance. Journal of Energy Resources Technology, 115, 70-75. https://doi.org/10.1115/1.2905972

[28] Waterman, P. (2002) Virtual Testing. Computer Graphics World, 25, 26.

[29] Aparicio, F., Jiménez, F. and Sánchez, J. (2009) Development and Use of Vehicle Dynamics Simulation Software as Support for Road Vehicles Theory Teaching. Computer Applications in Engineering Education, 17, 467-478. https://doi.org/10.1002/cae.20245

[30] Calvo, J.A., Boada, M.J., Díaz, V. and Olmeda, E. (2008) SIMPERF: SIMULINKBased Educational Software for Vehicle's Performance Estimation. Computer Applications in Engineering Education, 17, 139-147. https://doi.org/10.1002/cae.20191

[31] Bylund, N. (2005) ADRIAN: A Software for Computing the Stiffness of Automotive Joints and Its Application in the Product Development Process. Journal of Computing and Information Science in Engineering, 5, 388-393. https://doi.org/10.1115/1.1870019

[32] Jiménez, F., LópezJosé, M., Sánchez, J. and Cobos, P. (2011) Simulation and Testing of Hybrid Vehicle Function as Part of a Multidisciplinary Training. Computer Applications in Engineering Education, 19, 604-614. https://doi.org/10.1002/cae.20341

[33] Fabian, M., Puškár, M., Boslai, R., Kopas, M., Kender, Š. and Huňady, R. (2018) Design of Experimental Vehicle Specified for Competition Shell Eco-Marathon 2017 According to Principles of Car Body Digitisation Based on Views in 2D Using the Intuitive Tool Imagine \& Shape CATIA V5. Advances in Engineering Software, 115, 413-428. https://doi.org/10.1016/j.advengsoft.2017.10.006

[34] Agrawal, H., Gopalakrishnan, R. and Rivard, C. (1994) Durability Assessment of Large Automotive Body Structures Using Fatigue Life Analysis Procedure (FLAP). International Journal of Computer Applications in Technology, 7, 250-270.

[35] Du, H.A. and Tang, S.C. (1982) Minimum Weight Design of a Car Trunk Deck-Lid Subject to Overall Stiffness Constraints. Journal of Mechanical Design, 104, 831-836. https://doi.org/10.1115/1.3256444

[36] Keller, E., Ozalp, B.T. and Strasser H. (2007) Maximum Torque and Muscle Strain While Using Screwdrivers with Clean and Contaminated Surfaces in Bi-Directional use. In: Assessment of the Ergonomic Quality of Hand-Held Tools and Computer Input Devices, IOS Press, Amsterdam, 173-181.

[37] Ozalp, B.T. and Babalik, F.C. (2005) Ergonomic Evaluation of Screwdriver Handles under Different Working Conditions. Occupational Ergonomics, 5, 187-203.

[38] Henkel, W. (1995) LIFT-O-MAT, Stabillus GmbH.

[39] Deitel, P.J. and Deitel, H.M. (2008) Visual Basic 2008 How to Program. Prentice Hall, USA. 


\section{Nomenclature}

$\mathrm{C}_{\mathrm{gs}}$ : Gas Spring Compression Coefficient

$\mathrm{C}_{\text {gs-p }}$ : Gas Spring Position Based Compression Coefficient

$\mathrm{F}_{\mathrm{gs}-\mathrm{f}}:$ Gas Spring Friction Force $(\mathrm{N})$

$\mathrm{F}_{\mathrm{gs}-\mathrm{i}}$ : Gas Spring Internal Force $(\mathrm{N})$

$\mathrm{F}_{\mathrm{gs-n}}$ : Gas Spring Nominal Force $(\mathrm{N})$

$\mathrm{F}_{\mathrm{gs}-\mathrm{o}}$ : Gas Spring Output Force $(\mathrm{N})$

$\mathrm{F}_{\text {man-cl }}$ : Manual Force during Closing (N)

$\mathrm{F}_{\text {man-op }}$ : Manual Force during Opening $(\mathrm{N})$

M: Moment (N.m)

$\mathrm{M}_{\mathrm{w}}$ : Weight Moment $(\mathrm{N} \cdot \mathrm{m})$

$\mathrm{M}_{\mathrm{gs}}$ : Gas Spring Moment $(\mathrm{N} \cdot \mathrm{m})$

$\mathrm{T}$ : Working Temperature $\left({ }^{\circ} \mathrm{C}\right)$

$\mathrm{W}_{\mathrm{T}}$ : Tailgate Weight $(\mathrm{N})$

\section{Symbols}

$\Delta \zeta_{\mathrm{gs}}:$ Gas Spring Length Change (m)

$\Delta \zeta_{\text {gs-max }}:$ Gas Spring Maximum Length Change (m)

$\theta$. Tailgate Position Angle (Deg)

$\theta_{\text {cr: }}$ Tailgate Critical Position Angle (Deg)

$\theta_{\mathrm{fo}}:$ Tailgate Fully Open Angle (Deg)

$\zeta_{\mathrm{gs}}$ : Gas Spring Length (m)

$\zeta_{\text {gs-c }}:$ Gas Spring Length at Closed Position (m)

$\zeta_{\text {gs-fo }}$ : Gas Spring Length at Fully Open Position (m) 